\title{
A HOLISTIC SOCIAL COMMERCE FRAMEWORK FOR SAUDI ARABIA
}

\author{
Mohammed Aljaafari \\ Curtin University, WA, Australia
}

\begin{abstract}
The evolution of social networking and the significant growth of e-commerce has changed the nature of e-commerce interaction between customers and organizations. This evolution has produced a new form of e-commerce known as named "social commerce" (SC). In Saudi Arabia, social networking usage has increased rapidly and has begun to be an indispensable part of everyday life. The current literature indicates that social commerce has not been studied extensively and the majority of the studies on social commerce have focused mainly on the investigation of specific factors. However, in this study, the researcher intends to investigate a comprehensive range of factors including Organization Characteristics factors, HCI factors, Social factors, Psychological factors and Cultural factors. Hence, the purpose of this study is to identify the major factors that influence the customers' attitude to the adoption of s-commerce in Saudi Arabia. A new initial holistic framework will be developed for s-commerce in Saudi Arabia based on an extensive literature review. A mixed methods approach suggested for this research. This study will provide a holistic framework that will benefit stakeholders such as companies, organizations and governments by suggesting ways to encourage customers to adopt SC and find practical solutions to improve the use of SC in Kingdom Saudi Arabia (KSA) as well as those in developing countries, especially the Gulf Cooperation Council countries.
\end{abstract}

\section{KEYWORDS}

Social Commerce, Social Networking, E-commerce, Online Shopping, Consumers’ Attitude

\section{INTRODUCTION}

Electronic commerce, commonly known as e-commerce is the process of online buying and selling of goods and services (Khan, 2016). According to numerous statistical data study (99firms, 2019, Law, 2019, Statista, 2019c, Webalive, 2019), there are a growing number of consumers use the internet to gather data regarding the online goods and services as well as buying goods and services (Gatautis and Medziausiene, 2014). An almost 1.8 billion population of the entire world purchase the online goods in the year 2018 (Statista, 2019b). Many businesses consider e-commerce as an essentially element to hold their place in the competitive markets; it is also consider as a significant economic growth factor (Makki and Chang, 2015). In 2019, Saudi Arabia e-commerce purchases grow gradually to US\$7,141 million (Statista, 2019a). According to statistics, in 2019 there are around 23 million users on different social networking in Saudi Arabia (Gmi_Blogger, 2019). The popularity of social networking along with the significant growth of e-commerce is having a massive effect on the world economy. The change in the users' shopping behaviour has evolved a new form of e-commerce, named "social commerce" (Busalim and Hussin, 2016). This recent concept can be the future interest for researchers (Liang and Turban, 2011). Social commerce (s-commerce) is a phenomenon that has continued to evolve since its initial emergence in 2005 (Wang and Zhang, 2012). The first paper to discuss the concept of s-commerce was published in 2006 (Beisel, 2006, Han et al., 2018). In practice, the first formal beginning of SC was in 2009 with the opening of the flowers.com Facebook store (Busalim and Hussin, 2016). Numerous researchers consider the SC as an extended part of traditional e-commerce or a new development of it (Han et al., 2018). S-commerce is actually a subset of e-commerce, that uses the social networking platforms as a bridge to e-commerce to facilitate the online buying and selling of products and services via Internet technologies (Noh et al., 2013). 


\section{LITERATURE REVIEW}

This section reviews the current literature relating to the factors relevant to the proposed s-commerce framework for Saudi Arabia (see Figure 1).

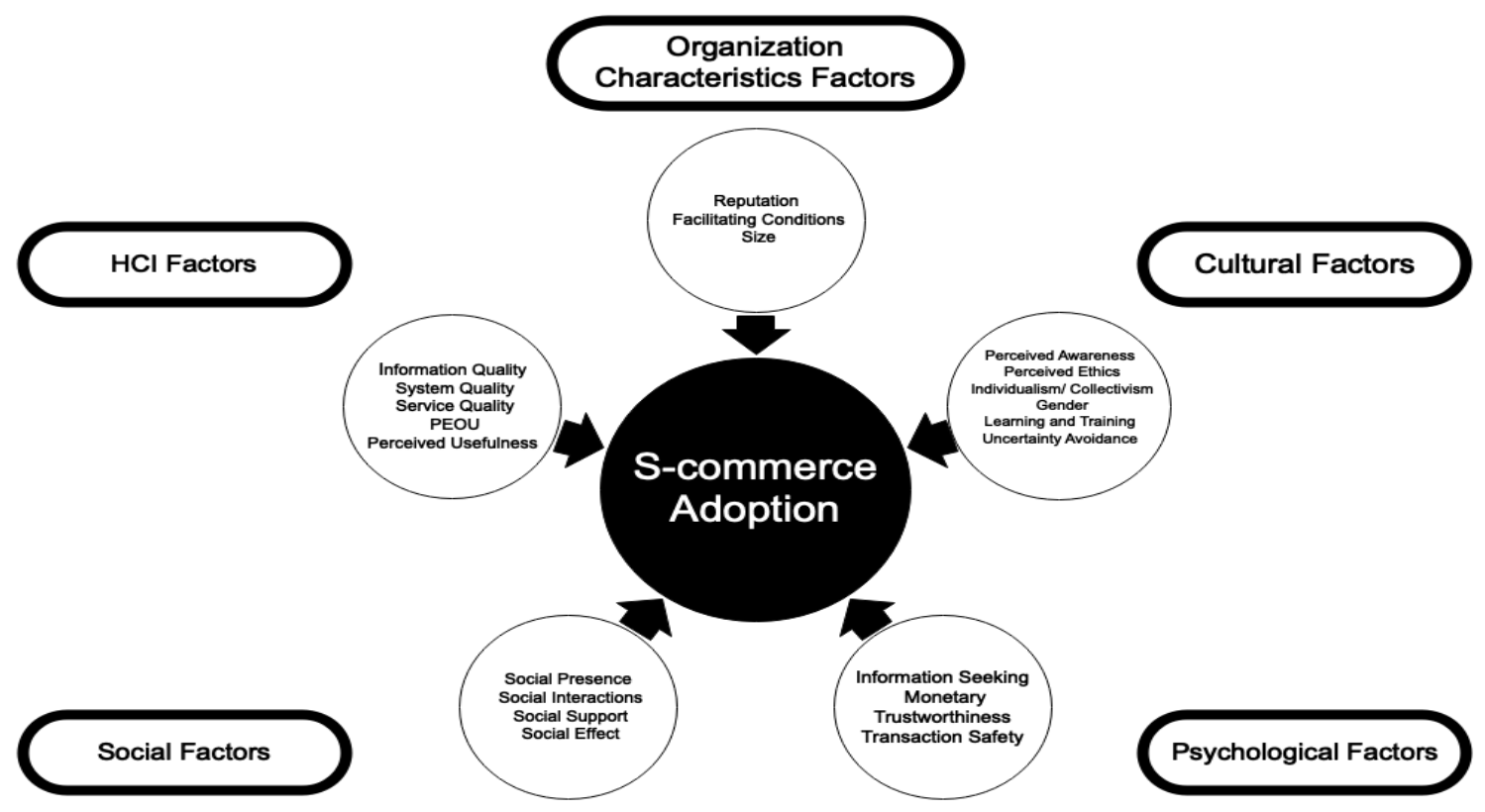

Figure 1. Initial holistic s-commerce framework for users in Saudi Arabia

\subsection{Organization's Characteristics Factors}

In terms of the factors relating to an organization's characteristics, the first factor is the organization's reputation which is the degree to which consumers' perceive that an organization is reliable and concerned about its clients ( $\mathrm{Li}$ et al., 2018). Many e-retailers believe that excellent reputation is a significant factor that inspires trust in consumers ( $\mathrm{Li}$ et al., 2018). The next dimension is facilitating conditions which refers to the extent to which a person's perception that an organizational structure and technical infrastructure are available to facilitate system use. This dimension examines the extent to which a customer believes that the social networks, as a workplace, support the usage of social commerce (Choi, 2019). The size of an s-commerce organization is the last variable, since the user might consider the size of the social commerce organization in terms of its share of the market. The large size of online organizations that offer online transactions will increase users' confidence because they expect to encounter only minor risks from their operations (Kim and Park, 2013).

\subsection{Human Computer Interaction Factors}

The quality of a website is a significant factor in determining the success of a social networking site (SNS) and usage behaviour. S-commerce includes using an SNS for commercial transactions. The quality of a website can be measured by three factors: information quality, system quality, and service quality. The system quality is associated with the desired and essential capabilities of a website such as its reliability, availability and response time (Hsu et al., 2017). On the other hand, information quality determines the accuracy, completeness, and timeliness of the website content (Abed, 2016). The final factor is service quality, which indicates the timeliness of responses when a consumer accesses supports and services provided through the website by the service provider (Hsu et al., 2017). The excellent quality of a social networking site will encourage consumers to believe that the platform is a valuable avenue for social 
interactions, and it could encourage users to continue using the platform for the exchange of information (Ahn et al., 2007, Teo et al., 2008).

Another HCI factor is perceived usefulness which is the degree to which consumers perceive that a new technology could improve performance (Davis, 1989). In term of s-commerce, Al-Adwan (2019), Bounkhong (2017) claimed that perceived usefulness has a positive impact on consumers' behavioural intention to adopt social commerce.

Like the perceived usefulness factor, the perceived ease of use (PEOU) is considered to be another vital factor in a variety of innovative technology researches where TAM theory was applied. PEOU refers to the extent to which an individual perceives that using a specific system will require little effort (Davis, 1989). The positive influence of this PEOU on behavioural intention has been proven by numerous studies related to the new technologies (Hajli et al., 2017b, Lu, 2017).

\subsection{Social Factors}

Social commerce mainly concerns the usage of social networks. Thus, a person's behaviour is influenced by the social factors that encourage collaboration and communication between individuals (Lal, 2017). In this study, social presence, social interactions, social support and social effect, have been identified as the major contributing factors that influence a person's decision regarding the use of SC. The first variable of social factors is social presence, which is associated with the ability of a website to elicit a feeling of warmth and sociability (Al-Adwan and Kokash, 2019). Social presence is considered as a prime concept in SC sites (Hajli et al., 2017a). The second factor is social interactions. The ease of interaction between buyers and sellers, without any constraints being imposed due to time or space, is considered to be a unique aspect of online shopping (Kim and Joo, 2001). The consumers who interact socially more with each other on the social networking platforms, have stronger feelings of closeness and familiarity with each other. Thus, there is more likelihood of the user's purchasing intention being influenced by the social networks community ( $\mathrm{Ng}, 2013)$. The third social factors variable is social support that is explained by Cobb (1976) as being perceived love, care, and support obtained from individuals within a group. In one community, it is likely that an individual will receive support from peers and friends (Hajli, 2019). When community members realize that their participation in online communities will strengthen their reputation, they will like to participate by their experiences and information (Hajli and Sims, 2015). Several studies (Hajli and Sims, 2015, Liang et al., 2011) indicated that users' SC intentions are influenced by online social support. The last social factor is social effect. Shin (2013) claimed that online customers' behaviour is strongly affected by those individuals whom they know and trust. This implies that social effect is a vital behavioural antecedent to the adoption of SC (Akman and Mishra, 2017).

\subsection{Psychological Factors}

In this study, information seeking, monetary considerations, trustworthiness, and transaction safety, have been identified as psychological factors that influence the adoption of SC. Firstly, seeking information related to s-commerce refers to an individual's efforts to acquire information related to any product or online sellers on SNSs such as ratings, reviews, and recommendations to facilitate purchasing decisions (Hajli et al., 2017a). A consumer's knowledge about a product can be enhanced by seeking and acquiring SC information from a plethora of sources available online. Subsequently, this additional knowledge about a specific product facilitates the customer's decision-making and increases the individual's purchase intentions (Chiou et al., 2002, Turcotte et al., 2015). Moreover, one of the most important factors influencing an individual's purchasing decisions is the monetary issue (Kim and Park, 2012). Maia et al. (2019) have mentioned that one of the significant advantages of online shopping is the offering of low-priced services or products, which can improve the level of customer trust in online organizations. The third psychological factor is trustworthiness. Trust is considered to be the key to the successful establishment of a long-term relationship and it becomes even more important in the context of online platforms because much uncertainty surrounds the online environment (Lin et al., 2018). In s-commerce, the users seek advice and reliable information from SNSs and members whom they can trust regarding their online experiences of purchasing a product or using service (Chen and Shen, 2015). Thus, in this study, Community Commitment, Trust in Marketplace, Trust towards Members and Trust in Sellers have been identified as the trustworthiness factor that could influence an individual's decision to use SC. The last psychological factor is the transaction safety that refers to the degree to which SC consumers perceive that SC supports a high level of security related to both transactions and 
transaction-related information (Maia et al., 2019). According to previous researches, transaction safety is a significant factor that determines the users' trust in e-commerce organizations (Cheung and Lee, 2006, Kim et al., 2008).

\subsection{Cultural Factors}

Globalization in the business world has increased dramatically; therefore, culture now plays a considerable role in all the business operations (Straub et al., 1997) and it directly impacts upon the consumers' adoption of technologies (Sheikh et al., 2017). As suggested by (Biucky et al., 2017), the acceptance and adoption of information technologies are influenced by cultural factors. This study focuses on five dimensions of culture: perceived awareness, perceived ethics, individualism / collectivism, gender and learning and training, which are the most relevant to this study.

\section{RESEARCH METHODOLOGY}

In the field of information systems, mixed methods design can provide a wider range of data that enable IS researchers to deal with such issues (Venkatesh et al., 2013). Moreover, the mixed methods approach provides a more in-depth comprehension of the research issue and questions than does a single method (Creswell and Clark, 2017). One type of mixed methods strategy known as "sequential explanatory research design" suggested in this study. This strategy involves two phases of data collection and analysis: a quantitative phase, followed by a qualitative phase (Saunders, 2016). In this study, the quantitative data should be collected first via an online survey to assist the researcher to identify the factors which should be added to the initial social commerce adoption framework. After that, the qualitative method should be applied by conducting semi-structured interviews to validate the improve of the social commerce adoption framework and to ensure that it is represented in a comprehensive manner.

The target population for the online survey can include any social network users in Saudi Arabia who have at least one social networking account.

A pilot survey questionnaire can be distributed before the online survey is conducted in order to ensure the survey questions' reliability and validity. A pilot test helps to refine the questionnaire and gives the researcher some indication of the validity and the likely reliability of the survey questions (Saunders, 2016).

After that, the researcher can conduct semi-structured interviews with e-commerce experts or proprietors to gather the data required for the purpose of achieving the research objectives and supporting the data obtained from the online survey results.

\section{CONCLUSION}

As a conclusion, the main purpose of this research is to makes new theoretical and academic contributions to the current literature on the significant factors required for the successful implementation of social commerce in Saudi Arabia. The study will contribute to the researches on social commerce adoption by adding information about the factors that affect consumer behavior in terms of using social commerce in the KSA. To the best of this researcher's knowledge, none of the previous researches has reviewed all these factors comprehensively. Thus, there is a need for a better understanding of the major factors that affect the consumers' online behavior.

In addition, in terms of practical application, it is anticipated that the study's outcomes will benefit stakeholders such as companies, organizations and governments as they will provide guidance on how to encourage customers to adopt social commerce and find practical solutions to improve the use of s-commerce in KSA. Furthermore, this research is aligned with the objectives of Saudi Vision 2030, a project map for strengthening the Saudi economy by diversifying income resources. One of the goals of Saudi Vision 2030 is to promote economic growth by empowering Saudi entrepreneurs (VISION). Hence, this research contributes to the Vision and has practical implications for Saudi internet entrepreneurs by offering recommendations that will encourage consumers to adopt SC in Saudi Arabia. Furthermore, this holistic framework could be applied in the Gulf Cooperation Council (GCC) countries as they have many factors in common such as culture, religion, social, languages, and economic and financial systems. 
Finally, although the proposed holistic framework offers practical and theoretical contributions, its factors and relationships need to be empirically tested. In future work, we plan to extend the current research by examine the proposed framework by using a mixed-methods to determine the factors that influence customers' behaviour toward SC in KSA. Finally, this paper is part of a broader research project that we will publish in the future.

\section{REFERENCES}

99FIRMS. 2019. General Stats \& Facts [Online]. Available: https://99firms.com/blog/ecommerce-statistics [Accessed Sep 20, 2019].

Abed, S. S. 2016. Exploring factors influencing consumer intention to use social commerce. 27811745 Ph.D., Swansea University (United Kingdom).

Ahn, T., Ryu, S. \& Han, I. 2007. The impact of Web quality and playfulness on user acceptance of online retailing. Information \& management, 44, 263-275.

Akman, I. \& Mishra, A. 2017. Factors influencing consumer intention in social commerce adoption. Information Technology \& People, 30, 356-370.

Al-Adwan, A. S. 2019. Revealing the influential factors driving social commerce adoption. Interdisciplinary Journal of Information, Knowledge, and Management, 14, 295-324.

Al-Adwan, A. S. \& Kokash, H. 2019. The Driving Forces of Facebook Social Commerce. Journal of Theoretical and Applied Electronic Commerce Research, 14, 15-32.

Beisel, D. 2006. The emerging field of social commerce and social shopping. Genuine VC.

Biucky, S. T., Abdolvand, N. \& Harandi, S. R. 2017. The Effects of Perceived Risk on Social Commerce Adoption Based on the TAM Model. International Journal of Electronic Commerce Studies, 8, 173-196.

Bounkhong, T. 2017. Factors Affecting Intentions to Use Social Commerce in Shopping for Fashion Products. 10275567 M.S., University of Arkansas.

Busalim, A. H. \& Hussin, A. R. C. 2016. Understanding social commerce: A systematic literature review and directions for further research. International Journal of Information Management, 36, 1075-1088.

Chen, J. \& Shen, X.-L. 2015. Consumers' decisions in social commerce context: An empirical investigation. Decision Support Systems, 79, 55-64.

Cheung, C. M. \& Lee, M. K. 2006. Understanding consumer trust in Internet shopping: A multidisciplinary approach. Journal of the American society for Information Science and Technology, 57, 479-492.

Chiou, J.-S., Droge, C. \& Hanvanich, S. 2002. Does customer knowledge affect how loyalty is formed? Journal of Service Research, 5, 113-124.

Choi, Y. 2019. The study of antecedents of aesthetic experience and consumer purchase intention in social commerce. International Journal of E-Services and Mobile Applications, 11, 67-78.

Cobb, S. 1976. Social support as a moderator of life stress. Psychosomatic medicine.

Creswell, J. W. \& Clark, V. L. P. 2017. Designing and conducting mixed methods research, Sage publications.

Davis, F. D. 1989. Perceived usefulness, perceived ease of use, and user acceptance of information technology. MIS quarterly, 319-340.

Gatautis, R. \& Medziausiene, A. 2014. Factors Affecting Social Commerce Acceptance in Lithuania. Procedia - Social and Behavioral Sciences, 110, 1235-1242.

GMI_BLOGGER. 2019. Saudi Arabia Social Media Statistics 2019 [Online]. Available: https://www.globalmediainsight.com/blog/saudi-arabia-social-media-statistics/ [Accessed Oct 12, 2019].

Hajli, N. 2019. The impact of positive valence and negative valence on social commerce purchase intention. Information Technology \& People, 33, 774-791.

Hajli, N. \& Sims, J. 2015. Social commerce: The transfer of power from sellers to buyers. Technological Forecasting and Social Change, 94, 350-358.

Hajli, N., Sims, J., Zadeh, A. H. \& Richard, M.-O. 2017a. A social commerce investigation of the role of trust in a social networking site on purchase intentions. Journal of Business Research, 71, 133-141.

Hajli, N., Wang, Y., Tajvidi, M. \& Hajli, M. S. 2017b. People, Technologies, and Organizations Interactions in a Social Commerce Era. IEEE Transactions on Engineering Management, 64, 594-604.

Han, H., Xu, H. \& Chen, H. 2018. Social commerce: A systematic review and data synthesis. Electronic Commerce Research and Applications, 30, 38-50.

Hsu, C. L., Chang, K. C., Kuo, N. T. \& Cheng, Y. S. 2017. The mediating effect of flow experience on social shopping behavior. Information Development, 33, 243-256. 
Khan, A. G. 2016. Electronic commerce: A study on benefits and challenges in an emerging economy. Global Journal of Management and Business Research.

Kim, D. J., Ferrin, D. L. \& Rao, H. R. 2008. A trust-based consumer decision-making model in electronic commerce: The role of trust, perceived risk, and their antecedents. Decision support systems, 44, 544-564.

Kim, S. \& Park, H. 2012. Effects of various characteristics of social commerce (s-commerce) on consumers' trust and trust performance. International Journal of Information Management.

Kim, S. \& Park, H. 2013. Effects of various characteristics of social commerce (s-commerce) on consumers' trust and trust performance. International Journal of Information Management, 33, 318-332.

Kim, S. Y. \& Joo, Y. H. 2001. Perceived Interactivity and Web site Loyalty/On the Role of Flow as a Mediating Variable. Journal of Consumer Studies, 12, 185-208.

Lal, P. 2017. Analyzing determinants influencing an individual's intention to use social commerce website. Future Business Journal, 3, 70-85.

Law, T. J. 2019. 19 Powerful Ecommerce Statistics That Will Guide Your Strategy in 2019 [Online]. Available: https://www.oberlo.com/blog/ecommerce-statistics-guide-your-strategy [Accessed Oct 3, 2019].

Li, Q., Ni, L. \& Li, E. Y. 2018. Does friendship quality matter in social commerce? An experimental study of its effect on purchase intention. Electronic Commerce Research, 18, 693-717.

Liang, T.-P., Ho, Y.-T., Li, Y.-W. \& Turban, E. 2011. What drives social commerce: The role of social support and relationship quality. International journal of electronic commerce, 16, 69-90.

Liang, T.-P. \& Turban, E. 2011. Introduction to the Special Issue Social Commerce: A Research Framework for Social Commerce. International Journal of Electronic Commerce, 16, 5-14.

Lin, J., Li, L., Yan, Y. \& Turel, O. 2018. Understanding Chinese consumer engagement in social commerce. Internet Research, 28, 2-22.

Lu, W. 2017. An Examination of Social Online Shopping Attitudes of Undergraduate Students Enrolled in the Department of Agricultural Leadership, Education, and Communications at Texas A\&M University. 10662557 Ph.D., Texas A\&M University.

Maia, C. R., Lunardi, G. L., Dolci, D. \& D'avila, L. C. 2019. Competitive Price and Trust as Determinants of Purchase Intention in Social Commerce. Brazilian Administration Review, 16, 1-24.

Makki, E. \& Chang, L.-C. 2015. Understanding the effects of social media and mobile usage on e-commerce: an exploratory study in Saudi Arabia. International management review, 11, 98.

NG, C. S.-P. 2013. Intention to purchase on social commerce websites across cultures: A cross-regional study. Information \& Management, 50, 609-620.

Noh, M., Lee, K., Kim, S. \& Garrison, G. 2013. Effects of collectivism on actual s-commerce use and the moderating effect of price consciousness. Journal of Electronic Commerce Research, 14, 244.

Saunders, M. A. 2016. Research methods for business students / Mark Saunders, Philip Lewis, Adrian Thornhill, Harlow Pearson Education.

Sheikh, Z., Islam, T., Rana, S., Hameed, Z. \& Saeed, U. 2017. Acceptance of social commerce framework in Saudi Arabia. Telematics and Informatics, 34, 1693-1708.

Shin, D.-H. 2013. User experience in social commerce: in friends we trust. Behaviour \& information technology, 32, 52-67.

STATISTA. 2019a. E-commerce in Saudi Arabia [Online]. Available: https://www.statista.com/outlook/243/110/ecommerce/saudi-arabia [Accessed Oct 10, 2019].

STATISTA. 2019b. E-commerce worldwide - Statistics \& Facts [Online]. Available: https://www.statista.com/statistics/534123/e-commerce-share-of-retail-sales-worldwide/ [Accessed Dec 19, 2019].

STATISTA. 2019c. Number of digital buyers worldwide from 2014 to 2021 [Online]. Available: https://www.statista.com/statistics/251666/number-of-digital-buyers-worldwide/ [Accessed Sep 18, 2019].

Straub, D., Keil, M. \& Brenner, W. 1997. Testing the technology acceptance model across cultures: A three country study. Information \& management, 33, 1-11.

Teo, T. S., Srivastava, S. C. \& Jiang, L. 2008. Trust and electronic government success: An empirical study. Journal of management information systems, 25, 99-132.

Turcotte, J., York, C., Irving, J., Scholl, R. M. \& Pingree, R. J. 2015. News recommendations from social media opinion leaders: Effects on media trust and information seeking. Journal of Computer-Mediated Communication, 20, 520-535.

Venkatesh, V., Brown, S. A. \& Bala, H. 2013. Bridging the qualitative-quantitative divide: Guidelines for conducting mixed methods research in information systems. MIS quarterly, 21-54.

Wang, C. \& Zhang, P. 2012. The evolution of social commerce: The people, management, technology, and information dimensions. Communications of the Association for Information Systems, 31, 105-127.

WEBALIVE. 2019. The State of Australia's Ecommerce in 2019 [Online]. Available: https://www.webalive.com.au/ecommerce-statistics-australia/ [Accessed Sep 25, 2019]. 